\title{
The Well-being and Job Satisfaction of Secondary CLIL and Tertiary EMI Teachers in Austria
}

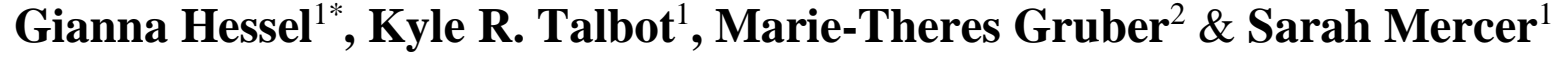 \\ ${ }^{1}$ University of Graz, ${ }^{2} \mathrm{KPH}$ Graz \\ *gianna.hessel@uni-graz.at
}

\begin{abstract}
Previous studies have highlighted the unique challenges that may threaten the well-being of teachers in CLIL/ EMI contexts, as well as unique opportunities that may positively impact their well-being (Moate, 2011; Pappa et al., 2017; Talbot et al., 2021). Results from Talbot et al. (2021) suggest that, in the Austrian context, the well-being of secondary CLIL teachers may be more at risk than that of tertiary EMI teachers. As such, the present study aimed to investigate this notion further through a comparative survey examining the well-being and job satisfaction of secondary CLIL and tertiary EMI teachers in Austria. In total, 123 secondary CLIL teachers and 219 tertiary EMI teachers completed the questionnaire survey. Results show that CLIL teachers tended to score consistently lower on several key dimensions related to well-being than EMI teachers, while the differences in job satisfaction were far less pronounced. Thus, the findings of this study lend empirical support to the notion that CLIL teachers at Austrian secondary schools may be more at risk in terms of their well-being than their colleagues at tertiary level. The survey data also provides valuable insights into teacher beliefs associated with professional well-being. An important implication for practice is that those teachers who felt more adequately trained to teach CLIL/EMI classes tended to report significantly higher professional well-being than their colleagues at both the secondary and tertiary level.
\end{abstract}

Keywords: CLIL, EMI, well-being, job satisfaction, language education, higher education, secondary schools, positive education 
CLIL/EMI settings are growing in the number of programs and in terms of geographical spread (Dearden, 2015), yet few studies report on how these contexts and professional roles may affect teachers' well-being and job satisfaction (see Hofstadler et al., 2020; Moate, 2011; Pappa et al., 2017; Talbot et al., 2021). Given how important teacher wellbeing is for their professional practice and personal happiness (Barber \& Mourshed, 2007; Day et al., 2007) it is vital to understand the potential impact that these new professional profiles may have.

In Europe, CLIL generally refers to educational settings where non-language subjects are taught through a different language than the home language of the students. At the tertiary level when these courses are taught in English, this is normally referred to as EMI. CLIL is defined as, "an educational approach where curricular content is taught through the medium of a foreign language, typically to students participating in some form of mainstream education at the primary, secondary, or tertiary level" (Dalton-Puffer, 2011, p. 183). CLIL is recognized for its intended "dual-focused" approach that privileges both language and content equally (Mehisto, Marsh \& Frigols, 2008, p. 9). In contrast, Macaro et al. (2018) define EMI as, "[t]he use of the English language to teach academic subjects (other than English itself) in countries or jurisdictions where the first language of the majority of the population is not English" (p. 37). Unlike CLIL settings, EMI settings typically do not prioritize content and language objectives equally (Aguilar, 2017; SchmidtUnterberger, 2018).

Both CLIL/EMI settings represent contexts where the expanded scope and demands of the responsibilities can impact how teachers feel in these roles. For instance, in these contexts, teachers need to demonstrate competency in both the subject and the language through which the subject is taught (Bovellan, 2014) and decide when and for what reason to shift between languages. It is therefore important to investigate how these settings and new roles may affect teachers' senses of professional well-being and job satisfaction. This paper reports on a survey investigating the well-being and job satisfaction of secondary-level content and language integrated learning (CLIL) teachers and tertiary-level English as a medium of instruction (EMI) teachers in Austria. This paper reports on one phase of a nationally funded Austrian research project on the well- being of CLIL/EMI teachers at the primary, secondary, and tertiary levels.

\section{LITERATURE REVIEW}

\section{Growth of CLIL and EMI Settings}

Both CLIL and EMI settings are growing quickly in terms of the number of programs and geographic locations (Dearden, 2015; Wächter \& Maiworm, 2014). Reasons for the spread of EMI programs in comparison to the spread of CLIL programs differ. Whereas CLIL in Europe is generally motivated by EU policies aiming to improve students' rates of multilingualism (Dalton-Puffer \& Nikula, 2006), Macaro and his colleagues (2018) explain that the reasons for the spread of EMI programs are "various and context-dependent" (p. 37). These reasons include a desire to internationalize universities, to garner university prestige, to recruit international students, and because of the status of English as a lingua franca (p. 37). Although a number of researchers (e.g., Aguilar, 2017; Dalton-Puffer, 2011) note that CLIL can also refer to the tertiary level, this paper explicitly refers to EMI when referring to the tertiary level, and CLIL when referring to the secondary level. The primary reason for this distinction is that CLIL settings generally aim to address language and content objectives (Coyle, Hood \& Marsh, 2010), whereas EMI focuses typically on content objectives only (Aguilar, 2017; Unterberger \& Wilhelmer, 2011; Schmidt-Unterberger, 2018).

\section{CLIL and EMI Settings in Austria}

Before describing the challenges and opportunities that CLIL/EMI settings engender for teachers, we provide a brief overview of the CLIL and EMI contexts in Austria. For CLIL at the secondary level, it is important to note that Austria has several types of schools, and that this affects how CLIL is implemented at each school type. There are three types of public secondary schools: Hauptschule and Neue Mittelschule (extended primary schooling), AHS (general secondary school) and BHS (vocational school). CLIL is only mandatory in one setting, and that is at HTLs (Höhere Technische Lehranstalt), a type of vocational school (BHS). HTL schools are required to teach 72 CLIL 
lessons per school year per subject by law (BGBl II Nr. 300, 2011).

While the AHS's curriculum mentions CLIL (BGB1. II Nr. 133/2000), the school can decide whether to implement it or not. Sometimes this decision is left up to the school and school officials (top-down) and, at other times, this choice is made by the teachers themselves (bottom-up). As such, the rationale for teachers teaching CLIL courses varies across and even within these school types. Another factor relevant to the Austrian CLIL context is that secondary school teachers generally have expertise in two subjects, for example, a teacher could teach both English and geography. This creates unique situations where those teachers who have expertise in a foreign language and another subject can combine their expertise for their CLIL teaching.

EMI in Europe tends to be realized in various ways that depend on local needs (Smit \& Dafouz, 2012). In terms of the Austrian EMI context, Austria has 34 universities (23 public and 11 private). In one study, Wächter and Maiworm (2014) estimated that approximately $1.8 \%$ students in Austria take part in EMI programs. Overall, Austria is ranked $10^{\text {th }}$ in the EU for the number of English teaching programs available at the university level (Wächter \& Maiworm, 2014). Wächter and Maiworm (2014) report that in the Central West Europe region, of which Austria is a part, the subject areas which EMI programs mainly belong are social sciences, business, and law (48\% bachelor programs; $30 \%$ master programs), followed by sciences (11\% bachelor programs; $33 \%$ master programs), engineering manufacturing and construction (4\% bachelor programs; $14 \%$ master programs), and other subject areas (19\% bachelor programs; $8 \%$ master programs). The remaining categories (i.e., agriculture, health and welfare, humanities and arts, services, and education) all are below $10 \%$ for both the bachelor and master level.

\section{CLIL and EMI: Challenges and Opportunities}

The rapid growth of both CLIL and EMI programs creates situations where teachers are often obliged to take on new roles and responsibilities - sometimes voluntarily and sometimes under institutional pressure to do so. Bovellan (2014) explains, "In addition to the challenges common to all teachers, expectations for CLIL teachers' capabilities seem to be even higher" (p. 32). These expectations include the need to be both a subject and language expert. These additional roles, responsibilities and expectations can affect the professional integrity of the teachers in these programs in positive, negative, or ambiguous ways (Hofstadler et al., 2020). In one study, Moate (2011) aimed to investigate how teaching in a foreign language impacted teachers' senses of professional integrity in the Finnish CLIL context. She found that for the teachers in her sample, maintaining professional integrity and continuity of practice across CLIL and non-CLIL courses was effortful but, ultimately, rewarding. Nevertheless, for these teachers, the transition from teaching a non-language subject in the L1 to CLIL teaching was taxing. Moate (2011) describes the transition as follows, "[t]he initial experience descriptions [of the teachers] are comparable to the crisis experience of newly qualified teachers" (p. 343). Fortunately, in her study, all of the participants eventually acclimatized to their CLIL teaching, and few of the initial concerns held by these teachers lasted over time. Another study in the Finnish CLIL context conducted by Pappa and her colleagues (2017) investigated how tensions and resources interact and impact how teachers experience their professional agency. Factors limiting teacher agency included teaching in the L2, classroom-related tensions, and the availability of resources for CLIL teaching. Factors facilitating teacher agency included autonomy, an openness to change, flexibility, and collegiality. Similar to Pappa et al. (2017), others have lamented about the lack of available resources for CLIL teachers (Bovellan, 2014; Cammarata \& Tedick, 2012), although material creation has also been shown to be an outlet for teachers to positively express creativity in their work (Hofstadler et al., 2020).

Mixed findings can also be found at the tertiary level for EMI teachers. For instance, in an early EMI study, Vinke, Snippe and Jochems (1998) explored what effects internationalization has had on universities. Specifically, they investigated the effects that teaching in English would have on international teachers and their quality of classroom instruction. According to Vinke and colleagues (1998), EMI teaching generally led to higher demands in terms of preparation time. Additionally, the majority of their survey respondents felt less capable of expressing themselves as accurately in their EMI courses (59\%). A more recent study by Aguilar (2017) aimed to understand how engineering lecturers teaching in English in Spain understood their work. Though these teachers generally perceived courses in 
English as being beneficial for their students, some were, "baffled about the extra workload they inadvertently had on their shoulders" (pp. 10-11). One major challenge for these teachers was linguistic insecurity; "For all the teachers but one [ $n=41]$, their main challenge was to improve their English fluency, which was the reason why teachers flatly refused any responsibility as English teachers. They felt slightly ashamed of their insufficient fluency..." (p. 10). However, her study also demonstrated that these teachers' relationships to teaching through English were not straightforward, "[a]s for their own benefits, lecturers were satisfied with their lecturing through English and... improved English fluency" (p. 10). It is apparent that both challenges and opportunities exist for EMI teachers; however, in two large-scale reviews of the implementation of EMI programs, Williams (2015) and Macaro et al. (2018) similarly concluded that the challenges related to implementing EMI currently outweigh the opportunities.

\section{Understanding and Measuring Well-being}

Various theories and frameworks for understanding and measuring well-being exist (e.g., Butler \& Kern, 2016; Deci \& Ryan, 1980; Diener et al., 1985; Hills \& Argyle, 2001; Kahneman et al., 2004; Nussbaum, 2003; Ryff, 1989; Seligman, 2011). For the purposes of this study, we take a multidimensional, eudemonic perspective of well-being based on Seligman's (2011) PERMA model. PERMA is an acronym standing for Positive Emotion, Engagement, Positive Relationships, Meaning, and Accomplishment. Together, these are the core constructs representing Seligman's (2011) well-being theory which focuses on a long-term perspective on meaning and purpose for happiness, rather than short-term hedonistic views of pleasure and happiness. It means that a person who experiences frequent positive emotions, is engaged in various domains in life, has quality relationships with other individuals, and accomplishes their goals would be considered to be flourishing, or in other words, experiencing high well-being. To measure PERMA, Butler and Kern (2016) developed a survey instrument called the 'PERMA Profiler'. The PERMA Profiler has been shown to correlate well with valid measures of subjective well-being (Goodman et al., 2017) and has now been used in a small number of studies (Ascenso, Perkins \& Williamon, 2018; Iasiello et al., 2017; MacIntyre et al., 2019). This study aims to measure CLIL/EMI teacher well-being in the work domain specifically. Accordingly, we adapted the PERMA Profiler instrument to reflect this domain specificity (e.g., "To what extent do you feel that your 'CLIL' teaching is valuable and worthwhile?; To what extent do you feel that teaching courses 'in English' is valuable and worthwhile?"). More information about our adapted scale can be found in the methodology section of this paper.

To measure our participants' job satisfaction, we adapted the Satisfaction with Life Scale (SWLS; Diener et al., 1985). The SWLS was designed to assess a person's satisfaction with life as a whole (Diener et al., 1985). A person's judgment of satisfaction with one's own life or a specified domain depends upon what that person perceives as an appropriate standard (Diener et al., 1985). As such, job satisfaction is centered on a subjective report by the individual. The SWLS has been demonstrated to be "a valid and reliable measure of life satisfaction, suited for use with a wide range of age groups and applications" (Pavot et al., 1991). For the purposes of our study, we were interested in the teachers' life satisfaction judgements in the professional domain. Thus, the adaptations to the items shifted the focus from life as a whole, to the professional domain specifically. Additional information about the adapted SWLS measure can be found in the methodology section of this article.

\section{Teacher Well-being and Job Satisfaction}

The unique conditions created by the implementation of CLIL/EMI programs necessitates a more thorough research agenda concerning the possible effects of these contexts on the teachers. This includes a more nuanced view of what conditions and factors allow teachers to succeed in their work. For teachers, a series of factors including national culture, language policy, localized school culture, colleagues and teachers' roles and responsibilities impact a teachers' senses of professional identity, and, ultimately, their well-being and job satisfaction (Day, 2017). Day (2017) argues that if, “... alongside their content and pedagogical knowledge, [teachers] have a strong moral purpose and direction, high self-efficacy, a strong sense of agency, motivation, job satisfaction and well-being, then their commitment to educating students to the best of their ability is likely to be high" (p. 31). There is indeed empirical evidence that lends support to this argument. Research 
suggests that teachers experiencing high well-being are more effective in their practice (Barber \& Mourshed, 2007; Caprara et al., 2006; Kunter et al., 2013). Bajorek, Gulliford and Taskila (2014), for instance, hypothesized that a stressed teacher with low job satisfaction would be unable to teach as effectively as a healthy and happy teacher with high job satisfaction. In their report, they cited several studies, one of which was a report by Dewberry and Briner (2007) that concluded that $8 \%$ of the variance among SAT (Student Attainment Test) could be attributed to the wellbeing of the students' teachers.

Indeed, teacher well-being is also important for students. In his forward to McIntyre, McIntyre and Francis' (2017) edited collection "Educator Stress", Greenberg (2017) argues, "In addition to facilitating learning, teachers are key agents of socialization, helping students reach their highest potential and develop into responsible citizens" (p. ix). One domain in which teachers profoundly impact their students is the way students feel about their classroom experiences. Teachers have an impact on the emotional states of students and their experiences of classroom enjoyment. For example, in one study, Frenzel et al. (2009) examined the relationship between teacher and student enjoyment. The results of this study suggested that they are positively related. Interestingly, the key variable mediating the positive relationship between teacher and student enjoyment was the teacher's displayed enthusiasm.

In addition to well-being, an individual's perception of job satisfaction impacts how they feel about their job and how they perform in it. In one study with 13,808 teacher participants, Ostroff (1992) found that organizations with more satisfied teachers tended to be more effective overall. This suggests that job satisfaction impacts both teachers as individuals as well as their organizations and schools. The same study also found strong relationships between satisfaction, job attitudes, and intentions to quit (Ostroff, 1992). More recently, Wright and Bonett's (2007) study examined how psychological well-being, job satisfaction, performance at work, and job turnover interacted. They found that well-being was the key moderating factor between job satisfaction and intention to quit. Judge and Klinger (2008) also emphasized the importance of the relationships between job satisfaction, job attitudes, and well-being. They argue, "the reciprocal nature of job attitudes and subjective well-being highlights the fact that a sound understanding of one domain is incomplete without due consideration of the other" (Judge \& Klinger, 2008, p. 407).

Finally, although most teachers do not suffer from burnout or a lack of motivation (Farber, 1994), rates of burnout as high as $50 \%$ have been reported in various contexts including Germany (Byrne, 1999). Burnout has been shown to be associated with ill health (Toker et al., 2012) and low student classroom performance (Brunsting, Sreckovic \& Lane, 2014). For the teachers themselves, results of a 2006 study conducted by Hakanen, Bakker and Schaufeli suggested that a lack of job resources and the inability to meet job demands may be related to teacher burnout. Teacher burnout has also been found to be associated with job dissatisfaction and poor occupational functioning (Burke, Greenglass \& Schwarzer, 1996). To conclude, Talbot and Mercer (forthcoming) argue that, "Given the centrality of teacher well-being to effective practice and learner achievement, it is a critical omission in our body of knowledge that key stakeholders in the field know so little about teacher psychology, and in particular, their well-being". We believe this is especially critical in CLIL and EMI contexts in which the effects of the particularities of these roles in the educators remain unclear and in part conflicting.

\section{Aims of the Present Study}

This chapter presents one phase of a larger mixed methods study exploring the well-being of CLIL/EMI teachers in Austria at various educational levels. In a chapter related to the current study, Talbot et al. (forthcoming) compared the well-being of secondary CLIL teachers to that of tertiary level EMI teachers in Austria. They argued that the wellbeing of secondary CLIL teachers may be more at risk than that of their EMI counterparts. The present study aimed to investigate this notion using quantitative means to compare CLIL and tertiary EMI teachers in Austria regarding their job satisfaction and CLIL/EMI specific well-being. The following research questions guided the study:

1) What are differences and similarities in the job satisfaction and professional well-being of secondary CLIL and tertiary EMI teachers? 
2) What CLIL-/EMI-related attitudes and beliefs may be associated with professional well-being and job satisfaction of secondary CLIL and tertiary EMI teachers?

\section{METHODOLOGY}

\section{Participants}

The participants in this study were 123 CLIL teachers and 219 EMI teachers working at Austrian secondary- and tertiary-level education institutions. Their participation in this study was voluntary. Of the secondary-level CLIL teachers, 58 were teaching at HTL (secondary school with technical orientation), 42 at AHS (general secondary school), while the remaining 20 were teaching at a range of other secondary schools, including BMS, HAK, HLW and NMS. As the latter group was rather small and varied in terms of secondary school type, our analysis at the secondary level focusses on comparisons between teachers working at AHS (general) and HTL (technical) secondary schools. The participants were recruited through homogenous purposive sampling. At the secondary level, the selection criteria were based on whether or not these teachers were CLIL teachers and at the tertiary level this depended on whether these teachers were teaching one or more classes in English. The research team emailed head teachers at secondary schools and also universities across Austria that were offering both bachelor's and master's programs in English. The call for responses was also shared among relevant professional networks and email lists. The first question of the table acted to remove participants that were not CLIL/EMI teachers (e.g., "Are you a tertiary instructor who teaches in English in Austria?"). Answering no to this discriminatory question would move those who did not fulfill the appropriate criteria to the end of the survey. Table 1 provides an overview of key background characteristics of teachers in both samples.

\section{The Survey Instrument}

The questionnaire contained a total of 57 items at the secondary level and 72 items at the tertiary level, which captured the participants' background characteristics (e.g., gender, age, teaching experience, institution), their perceived job satisfaction, professional well-being in relation to CLIL/EMI, and their beliefs about themselves as CLIL/EMI teachers, beliefs about students taught through CLIL/EMI, beliefs about their CLIL/EMI classes, and beliefs about the teaching materials available. These questionnaire items were mostly closed-ended and discrete. Adapted versions of the "PERMA Profiler" (Butler \& Kern, 2016) and the "Satisfaction with Life Scale" (SWLS) (Diener et al., 1985) were used in order to measure the teachers' perceived well-being in relation to their CLIL/EMI teaching and to their job satisfaction generally. The properties of these multi-item scales, including their internal consistency are described further in Table 2.

Within the domain of professional well-being, in addition to the five PERMA items, we also used the item "While teaching CLIL, how often do you feel anxious or nervous?" to elicit data on "negative emotion (N)". This item was also adapted from Butler and Kern (2016). In addition, we used the following discrete item to capture overall professional wellbeing among the surveyed CLIL/EMI teachers: "In sum, how happy would you say you are with your CLIL/EMI teaching?”.

\section{Procedures of Data Collection and Analysis}

The questionnaire was administered online through Google Forms between March-June 2018. Participants were informed that the survey was anonymous and that their participation was voluntary. They were also informed that data from the survey would inform policy, support and training. After the data collection was closed, all data were imported into SPSS 25 for descriptive and inferential statistical analysis. Descriptive statistical procedures were used to describe the two samples in terms of central tendency and spread on all variables of interest. Differences in perceived well-being, job-satisfaction, and CLIL-/EMIrelated beliefs between teachers in both groups were established using independent samples t-tests. A bootstrapping procedure (Efron \& Tibshirani, 1993) with bias-corrected and accelerated (BCa) 95\% confidence intervals was applied to all significance tests involving nonnormally distributed data. Bootstrapping is a procedure that controls for bias that may result from a non-normal sampling distribution, as is common with affective variables. It generates more robust parameter estimates and 
significance tests that are not contingent on assumptions of normality (Efron \& Tibshirani, 1993). Normality was examined using the skewness and kurtosis parameters $(<$ $2.0)$, the Shapiro-Wilk statistic $(p<.05)$, as well as a visual inspection of the histograms and normal quantile-quantile plots (Doane \& Seward, 2011). The results section below contains bootstrapped significance values, unless otherwise stated. Effect sizes (Cohen's $d$ ) are reported for all main effects.

Table 1. Overview of Key Background Characteristics

\begin{tabular}{|c|c|c|}
\hline & CLIL teachers & EMI teachers \\
\hline Total $N$ & 123 & 219 \\
\hline \multicolumn{3}{|l|}{ Gender } \\
\hline Female & $67(54.5 \%)$ & 99 (45.2\%) \\
\hline Male & $55(44.7 \%)$ & $117(53.4 \%)$ \\
\hline Not specified & $1(0.8 \%)$ & $3(1.4 \%)$ \\
\hline \multicolumn{3}{|l|}{ Age } \\
\hline 24 or younger & $2(1.6 \%)$ & $0(0.0 \%)$ \\
\hline $25-34$ & $26(21.1 \%)$ & $45(20.5 \%)$ \\
\hline $35-44$ & $24(19.5 \%)$ & $66(30.1 \%)$ \\
\hline $45-54$ & $37(30.1 \%)$ & $66(30.1 \%)$ \\
\hline $55-64$ & $30(24.4 \%)$ & $42(19.2 \%)$ \\
\hline $65-74$ & $3(2.4 \%)$ & $0(0.0 \%)$ \\
\hline 75 or older & $1(0.8 \%)$ & $0(0.0 \%)$ \\
\hline \multicolumn{3}{|c|}{ Years of teach. experience } \\
\hline $1-3$ & $21(17.1 \%)$ & $39(17.8 \%)$ \\
\hline $4-6$ & $13(10.6 \%)$ & $24(11 \%)$ \\
\hline $7-18$ & $45(36.6 \%)$ & $94(42.9 \%)$ \\
\hline $19-31$ & $31(25.2 \%)$ & $46(21.0 \%)$ \\
\hline $32-40$ & $12(9.8 \%)$ & $11(5.0 \%)$ \\
\hline 41 or more & $1(0.8 \%)$ & $5(2.3 \%)$ \\
\hline \multicolumn{3}{|c|}{ Years of teach. CLIL/EMI } \\
\hline $1-3$ & $42(34.1 \%)$ & $62(28.3 \%)$ \\
\hline $4-6$ & $37(30.1 \%)$ & 48 (21.9\%) \\
\hline $7-18$ & $39(31.7 \%)$ & $86(39.3 \%)$ \\
\hline $19-31$ & $4(3.3 \%)$ & $17(7.8 \%)$ \\
\hline $32-40$ & $1(0.8 \%)$ & $6(2.7 \%)$ \\
\hline 41 or more & $0(0.0 \%)$ & $0(0.0 \%)$ \\
\hline
\end{tabular}

Note. Figures represent number (\% of non-missing values) unless otherwise stated. 
Table 2. Description of the Multi-Item Scales with Internal Consistency Scores (Cronbach's Alpha)

\begin{tabular}{lllll}
\hline & $\begin{array}{l}\text { No. } \\
\text { of scale } \\
\text { items }\end{array}$ & $\begin{array}{l}\text { Cronbach's } \\
\text { alpha (sec./ } \\
\text { ter. level) }\end{array}$ & Example item & Source \\
\hline $\begin{array}{l}\text { PERMA } \\
\text { Profiler }\end{array}$ & 5 & $0.87 / 0.86$ & $\begin{array}{l}\text { To what extent do you feel that your CLIL } \\
\text { teaching is valuable and worthwhile? }\end{array}$ & $\begin{array}{l}\text { Adapted from Butler \& Kern } \\
(2016)\end{array}$ \\
SWLS & 5 & $0.85 / 0.87$ & $\begin{array}{l}\text { The conditions of my profession are } \\
\text { excellent }\end{array}$ & $\begin{array}{l}\text { Adapted from Diener et al., } \\
(1985)\end{array}$ \\
\hline
\end{tabular}

\section{RESULTS}

\section{Job Satisfaction and Professional Well-Being of Secondary CLIL and Tertiary EMI Teachers}

\section{Job Satisfaction}

Table 3 below displays the "Satisfaction with Life Scale (SWLS)" total, as well as the individual item scores for secondary CLIL and tertiary EMI teachers. The summative $S W L S$ scores (secondary CLIL: $M=25.87(S D=5.77$ ), tertiary EMI: $M=25.07(S D=6.08)$ ) indicate that the overall job satisfaction among teachers in both groups tended to be slightly above average, according to Pavot and
Diener's (1993) scoring method (e.g., "Individuals who score in this range like their lives and feel that things are going well" [p. 2]). As Table 3 shows, the between-group difference in overall job satisfaction was not significant. For the individual $S W L S$ items, no significant between-group differences emerged, except on item 5: "If I could live my life over, I would change almost nothing about my career path." EMI instructors showed a stronger tendency towards the neutral mid-point, while secondary CLIL teachers tended more towards agree $(p<.05)$. The size of this between-group difference is small according to the Cohen Scale (Cohen's $d=0.23$ ).

Table 3. Job Satisfaction Item Mean Scores for Secondary CLIL and Tertiary EMI Teachers

\begin{tabular}{|c|c|c|c|}
\hline Item & $\begin{array}{l}\text { Secondary } \\
M(\mathrm{SD})\end{array}$ & $\begin{array}{l}\text { Tertiary } \\
M(\mathrm{SD})\end{array}$ & Group mean difference \\
\hline In most ways my professional life is close to ideal. & $5.07(1.43)$ & $5.01(1.33)$ & $t(340)=0.38, p=.954$ \\
\hline The conditions of my profession are excellent. & $4.55(1.61)$ & $4.54(1.61)$ & $t(340)=0.05, p=.962$ \\
\hline I am satisfied with my job. & $5.84(1.29)$ & $5.62(1.21)$ & $t(340)=1.55, p=.123$ \\
\hline $\begin{array}{l}\text { So far, I have gotten the important things I want in my } \\
\text { career. }\end{array}$ & $5.33(1.39)$ & $5.21(1.51)$ & $t(340)=0.71, p=.468$ \\
\hline $\begin{array}{l}\text { If I could live my life over, I would change almost nothing } \\
\text { about my career path. }\end{array}$ & $5.08(1.61)$ & $4.69(1.75)$ & $t(340)=2.09, \boldsymbol{p}<.05$ \\
\hline SWLS summative score & $25.87(5.77)$ & $25.07(6.08)$ & $t(340)=1.18, p=.225$ \\
\hline
\end{tabular}

Note. Response scale ranges from 1 (strongly disagree) to 7 (strongly agree). 


\section{Professional Well-being}

Table 4 below provides an overview of the group mean scores and between-group differences in the PERMA dimensions Positive emotion, Engagement, Relationships, Meaning, Achievement, Negative emotion, and overall professional well-being experienced by CLIL secondary teachers and EMI tertiary teachers. Highly significant between-group differences emerged for all PERMA items (all $p<.001$ ), except personal engagement and the experience of negative emotions (anxiety and nervousness) during CLIL/EMI classes. With these two exceptions, the group of secondary-level CLIL teachers tended to show consistently lower PERMA scores, suggesting that they tend to experience lower professional well-being overall and in terms of experiencing positive emotion, the perceived quality of their relationships with CLIL colleagues, meaning and their sense of achievement as CLIL teachers, as compared to their colleagues at tertiary level. The largest between-group differences were observable in how often teachers felt that they managed to achieve the important CLIL-/EMI-related work goals they had set for themselves, and in the extent to which they felt that their CLIL/EMI teaching was valuable and worthwhile (both medium-sized effects, Cohen's $d=0.60$ ).

Table 4. Professional Well-being Item Mean Scores for Secondary CLIL and Tertiary EMI Teachers

\begin{tabular}{llll}
\hline Item & $\begin{array}{l}\text { Secondary } \\
\text { M/ SD }\end{array}$ & $\begin{array}{l}\text { Tertiary } \\
\text { M/ SD }\end{array}$ & Group mean difference \\
\hline $\begin{array}{l}\text { P While teaching CLIL/ in English, how often do you } \\
\text { feel positive? }\end{array}$ & $7.14(2.16)$ & $7.88(1.93)$ & $t(340)=-3.27, \boldsymbol{p}<.001$ \\
$\begin{array}{l}\text { E To what extent do you feel excited and interested by } \\
\text { your CLIL/EMI teaching? }\end{array}$ & $6.81(2.42)$ & $7.28(2.29)$ & $t(340)=-1.77, p=.086$ \\
$\begin{array}{l}\text { R How satisfied are you with your relationships with } \\
\text { CLIL/EMI colleagues? }\end{array}$ & $6.89(2.33)$ & $7.69(1.85)$ & $t(340)=-3.28, \boldsymbol{p}<.001$ \\
$\begin{array}{l}\text { M To what extent do you feel that your CLIL/EMI } \\
\text { teaching is valuable and worthwhile? }\end{array}$ & $7.06(2.66)$ & $8.42(2.00)$ & $t(340)=-4.97, \boldsymbol{p}<.001$ \\
$\begin{array}{l}\text { A How often do you achieve the important CLIL-/EMI- } \\
\text { related work goals you have set for yourself? }\end{array}$ & $6.53(2.07)$ & $7.66(1.78)$ & $t(340)=-5.10, \boldsymbol{p}<.001$ \\
$\begin{array}{l}\mathbf{N} \text { While teaching CLIL/EMI in English, how often do } \\
\text { you feel anxious or nervous? }\end{array}$ & $7.53(2.55)$ & $7.51(2.44)$ & $t(340)=0.76, p=.939$ \\
$\begin{array}{l}\text { Overall PERMA mean score (without N) } \\
\begin{array}{l}\text { In sum, how happy would you say you are with your } \\
\text { CLIL/EMI teaching? }\end{array}\end{array}$ & $6.88(1.84)$ & $7.78(1.47)$ & $t(340)=-4.66, \boldsymbol{p}<.001$ \\
\hline
\end{tabular}

Note. Response scale ranges from 1 (never/not at all) to 10 (always/completely).

Within the secondary level, further significant differences in professional well-being emerged between teachers employed at AHS (general secondary school) and HTL (secondary school with a technical orientation). As Table 5 shows, teachers employed at HTLs tended to score significantly less favorably on all PERMA items, including the experience of negative emotion during CLIL classes. The between-group differences were most pronounced in teachers' overall professional well-being, as well as in the extent to which teachers in both groups felt excited and interested by their CLIL teaching and believed that it was valuable and worthwhile (all differences $p<.001$ ). In contrast, no significant differences in overall job satisfaction were observable between teachers at HTL and AHS type of secondary schools. 
Table 5. Professional Well-being Item Mean (SD) Scores for AHS and HTL Teachers

\begin{tabular}{|c|c|c|c|}
\hline Item & $\begin{array}{l}\text { AHS } \\
M / S D\end{array}$ & $\begin{array}{l}\mathrm{HTL} \\
\mathrm{M} / \mathrm{SD}\end{array}$ & Group mean difference \\
\hline P While teaching CLIL, how often do you feel positive? & $7.76(1.48)$ & $6.64(2.59)$ & $t(98)=2.74, \boldsymbol{p}<.01$ \\
\hline $\begin{array}{l}\text { E To what extent do you feel excited and interested by } \\
\text { your CLIL teaching? }\end{array}$ & $7.79(2.02)$ & $5.81(2.57)$ & $t(98)=4.30, p<.001$ \\
\hline $\begin{array}{l}\text { R How satisfied are you with your relationships with CLIL } \\
\text { colleagues? }\end{array}$ & $7.57(2.28)$ & $6.64(2.39)$ & $t(98)=1.98, \boldsymbol{p}<.05$ \\
\hline $\begin{array}{l}\text { M To what extent do you feel that your CLIL teaching is } \\
\text { valuable and worthwhile? }\end{array}$ & $8.00(2.10)$ & $6.09(2.88)$ & $t(98)=3.85, \boldsymbol{p}<.001$ \\
\hline $\begin{array}{l}\text { A How often do you achieve the important CLIL-related } \\
\text { work goals you have set for yourself? }\end{array}$ & $7.19(1.93)$ & $6.14(2.06)$ & $t(98)=2.62, \boldsymbol{p}<.05$ \\
\hline $\begin{array}{l}\mathbf{N} \text { While teaching CLIL, how often do you feel anxious or } \\
\text { nervous? }\end{array}$ & $1.79(2.05)$ & $3.10(2.96)$ & $t(98)=2.63, \boldsymbol{p}<.01$ \\
\hline Overall PERMA mean score (without N) & $7.66(1.45)$ & $6.26(2.00)$ & $t(98)=3.86, \quad p<.001$ \\
\hline $\begin{array}{l}\text { In sum, how happy would you say you are with your CLIL } \\
\text { teaching? }\end{array}$ & $7.86(2.06)$ & $5.95(2.58)$ & $t(98)=3.97, \quad p<.001$ \\
\hline
\end{tabular}

Note. Response scale ranges from 1 (never/not at all) to 10 (always/completely).

Teachers' Beliefs and Other Factors Associated with Professional Well-being and Job Satisfaction

For both CLIL secondary teachers and tertiary EMI teachers, the perceived adequacy of training ("I have received adequate training to be a CLIL teacher") was significantly and positively associated with the teachers' overall PERMA scores (secondary: $r=.35$; tertiary: $r=.43$, both $p<.01$ ). In other words, teachers who felt more adequately trained for undertaking CLIL/EMI teaching, tended to experience higher overall professional well-being. Significantly in this regard, teachers at secondary level tended to feel less adequately trained for CLIL teaching than their colleagues at tertiary level $(p<.01)$.

Further to this, a number of teacher beliefs and attitudes were associated with the professional well-being of teachers at both the secondary and tertiary level. The extent to which the teachers believed that their students enjoyed the CLIL/EMI classes ( $r=.69 / r=.55)$, that CLIL/EMI classes were beneficial to their students' L2 development ( $r=.66$ / $r=.50)$, that teaching CLIL/EMI classes was enriching to their professional lives $(r=.61 / r=.50)$, and the enjoyment derived from creating their own CLIL/EMI materials $(r$ $=.67 / r=.48)$ were all "positively" associated with professional teacher well-being. The strongest negative correlates of professional well-being were perceived stress during CLIL/EMI teaching ( $r=-.44 / r=-.54)$ and endorsing the belief that CLIL/EMI teaching negatively affected the one's work-life balance $(r=-.51 / r=-.51)$.

Table 6 shows secondary CLIL and tertiary EMI teachers' endorsement of the beliefs and attitudes above that were found to be associated with overall professional wellbeing. In addition to feeling less adequately trained than their colleagues at the tertiary level, teachers at the secondary level tended to enjoy creating materials for their CLIL classes less, they tended to agree more that teaching CLIL classes was more stressful for them than teaching non-CLIL classes than their colleagues at tertiary level, and they tended to disagree less that teaching CLIL classes was contributing negatively to their work-life balance (all 
differences $p<.001$ ). In contrast, teachers at both levels showed a similar tendency to moderately agree that teaching CLIL/EMI classes had enriched their professional lives, and that they were beneficial to the English language development of their students.
Teachers in both groups were somewhat unsure whether their students were enjoying CLIL/EMI classes, with no clear tendency towards agree or disagree.

Table 6. Differences in Beliefs and Attitudes Related to Professional Well-being Among CLIL and EMI Teachers

\begin{tabular}{|c|c|c|c|}
\hline & $\begin{array}{l}\text { Secondary } \\
\text { M/ SD }\end{array}$ & $\begin{array}{l}\text { Tertiary } \\
\text { M/ SD }\end{array}$ & Group mean difference \\
\hline $\begin{array}{l}\text { I have received adequate training to be a CLIL } \\
\text { teacher/EMI instructor }\end{array}$ & $3.78(1.84)$ & $4.46(2.18)$ & $t(340)=-3.05, \boldsymbol{p}<.01$ \\
\hline $\begin{array}{l}\text { My pupils/ students seem to enjoy their CLIL/EMI } \\
\text { classes }\end{array}$ & $4.71(1.57)$ & $4.88(1.49)$ & $t(340)=-0.97, p=.331$ \\
\hline $\begin{array}{l}\text { I believe that CLIL/EMI is beneficial for pupils in respect } \\
\text { to their English language learning }\end{array}$ & $5.76(1.55)$ & $5.58(1.53)$ & $t(340)=-1.07, p=.289$ \\
\hline $\begin{array}{l}\text { Teaching CLIL/EMI classes has generally enriched my } \\
\text { professional life }\end{array}$ & $5.21(1.59)$ & $5.34(1.61)$ & $t(340)=-0.73, p=.466$ \\
\hline I enjoy creating materials for my CLIL/EMI classes & $4.49(1.79)$ & $5.24(1.68)$ & $t(340)=-3.82, p<.001$ \\
\hline $\begin{array}{l}\text { I find teaching CLIL/EMI classes more stressful than } \\
\text { teaching non-CLIL/EMI }\end{array}$ & $3.94(1.96)$ & $2.95(2.05)$ & $t(340)=-4.41, \boldsymbol{p}<.001$ \\
\hline $\begin{array}{l}\text { I feel that CLIL/EMI teaching negatively contributes to } \\
\text { my work-life balance }\end{array}$ & $2.73(1.89)$ & $1.95(1.55)$ & $t(340)=-3.91, \boldsymbol{p}<.001$ \\
\hline
\end{tabular}

Note. Response scale ranges from 1 (strongly disagree) to 7 (strongly agree).

Within the secondary level, AHS and HTL teachers also tended to differ in a number of CLIL-related beliefs and attitudes, all of which were associated with secondary CLIL teachers' professional well-being. As the between-group comparisons in Table 7 show, teachers at HTL schools tended to believe less strongly that CLIL was the best way to teach their subject $(p<.05)$, that CLIL is beneficial to their pupils' L2 development ( $p<.001)$, and that their pupils enjoyed their CLIL classes $(p<.001)$. Teachers at HTL type schools also tended to find CLIL teaching more stressful ( $p$ $<.05)$ than their colleagues at AHS institutions, and tended to feel less strongly that they had special status as a CLIL teacher at their school, and that the school administration and their colleagues viewed CLIL teaching favorably (all three differences $p<.01$ ).

Regarding beliefs and attitudes associated with overall job satisfaction, at the secondary level significant positive associations emerged between CLIL teachers' job satisfaction and beliefs that CLIL lessons were beneficial for the L2 development of their pupils $(r=.23)$ and that their pupils enjoyed the CLIL lessons $(r=.26$; both correlations $p<.01)$. Moreover, the possibility to create one's own CLIL teaching materials $(r=.25)$ and the enjoyment derived from this creative work $(r=.21)$ were positively associated with the overall job satisfaction of secondary CLIL teachers (both $p<.05$ ). At tertiary level, only the extent to which EMI teaching was perceived to negatively affect the instructor's work-life balance was inversely correlated with overall job satisfaction $(r=-.24$, $p<.01)$. Neither the CLIL/EMI teachers' age, nor years of teaching experience were significantly associated with professional well-being or job satisfaction. 
Table 7. Differences in Beliefs and Attitudes Related to Professional Well-being Between AHS and HTL Teachers

\begin{tabular}{|c|c|c|c|}
\hline Item & $\begin{array}{l}\text { AHS } \\
\mathrm{M} / \mathrm{SD}\end{array}$ & $\begin{array}{l}\mathrm{HTL} \\
\mathrm{M} / \mathrm{SD}\end{array}$ & Group mean difference \\
\hline $\begin{array}{l}\text { I believe that CLIL is the best way to teach my content } \\
\text { subject }\end{array}$ & $3.76(1.68)$ & $3.07(1.70)$ & $t(98)=2.03, p<.05$ \\
\hline $\begin{array}{l}\text { I believe that CLIL is beneficial for pupils in respect to their } \\
\text { language learning }\end{array}$ & $6.21(1.44)$ & $5.17(1.68)$ & $t(98)=3.33, \boldsymbol{p}<.001$ \\
\hline My pupils seem to enjoy their CLIL classes & $5.52(1.25)$ & $3.84(1.54)$ & $t(98)=5.99, \boldsymbol{p}<.001$ \\
\hline $\begin{array}{l}\text { I find teaching CLIL more stressful than teaching non-CLIL } \\
\text { classes }\end{array}$ & $4.40(1.88)$ & $3.67(2.04)$ & $t(98)=1.82, p<.05$ \\
\hline $\begin{array}{l}\text { I feel that I have a special status as a CLIL teacher at my } \\
\text { school }\end{array}$ & $3.57(1.91)$ & $2.52(1.66)$ & $t(98)=2.87, \boldsymbol{p}<.01$ \\
\hline $\begin{array}{l}\text { The teachers in my school generally have a favorable view } \\
\text { of CLIL }\end{array}$ & $4.43(1.40)$ & $3.64(1.53)$ & $t(98)=2.68, p<.01$ \\
\hline $\begin{array}{l}\text { My administration (Direktion) generally has a favorable } \\
\text { view of CLIL }\end{array}$ & $6.26(1.15)$ & $4.98(1.76)$ & $t(98)=4.39, p<.01$ \\
\hline
\end{tabular}

Note. Response scale ranges from 1 (strongly disagree) to 7 (strongly agree).

\section{DISCUSSION}

To our knowledge, the present study is the first to investigate the well-being and job satisfaction of secondary CLIL and tertiary EMI teachers in Austria through a nationwide questionnaire. The results point to important similarities and salient differences between the two groups in terms of their job attitudes and beliefs as well as their experiences of job satisfaction and professional well-being. Its findings also differ from previous research in important ways. For example, in contrast to previous research (e.g., Bricheno et al., 2009; Klassen \& Chiu, 2010) neither the CLIL/EMI teachers' age, nor their years of teaching experience were significantly associated with professional well-being or job satisfaction.

In terms of overall job satisfaction, secondary CLIL teachers and tertiary EMI teachers reportedly did not tend to differ as measured by a modified version of the Satisfaction with Life Scale (SWLS) (Diener et al., 1985). Job satisfaction has been referred to as a "decisive element" impacting teachers' beliefs and classroom practice (Caprara et al., 2003, p. 823). Therefore, an encouraging result of the present study is that both secondary CLIL and tertiary EMI teachers reported levels of job satisfaction that were above average (Pavot \& Diener, 1993). This means that in both samples, individuals scoring in this range feel like they are generally satisfied and that things are going well. Pavot and Diener (1993) note that individuals in this range are satisfied but not complacent, "in fact, growth and challenge might be part of the reason this person is satisfied" (p. 2).

Though secondary CLIL and tertiary EMI teachers did not differ significantly in terms of reported job satisfaction, different correlates of job satisfaction were found in the data. At the secondary level specifically, job satisfaction was positively associated with teachers' beliefs about their CLIL students. That is, when teachers believed their students were learning language and enjoying doing so, their feelings of job satisfaction were impacted in positive ways. Secondary CLIL teachers' feelings of job satisfaction were also positively associated with materials generation and the enjoyment that comes from this. This finding partially supports Hofstadler et al. (2020) in part. They found in their sample of Austrian CLIL teachers that materials creation was neither wholly positive or negative; it entailed more 
work for these teachers but also allowed them to express their creativity and feel pride and accomplishment in their work. Taken to together, these findings point to a delicate balance between extra preparation time and the enjoyment experienced when preparing for class or working on materials.

The most salient differences between the surveyed secondary CLIL and tertiary EMI teachers emerged in their reported senses of professional well-being as it pertained to their CLIL and EMI teaching. CLIL teachers at the secondary level tended to score significantly lower than their colleagues at the tertiary level on several key dimensions of well-being related to their professional lives. This included their well-being as CLIL teachers generally, the positive emotions they experienced while teaching their CLIL classes, and the experiences of meaning and senses of achievement they derived from their CLIL teaching. Thus, the findings of this study lend empirical support to the notion that CLIL teachers in Austrian secondary schools may be more at risk in terms of their professional well-being than their colleagues at the tertiary level (see also Talbot et al., 2021). Interestingly, an important social element also emerged, namely, that secondary CLIL teachers tended to score significantly lower than tertiary EMI teachers in the perceived quality of their relationships with CLIL colleagues. Future interventions to promote CLIL teacher well-being therefore would be well suited to addressing both social and psychological factors.

Further significant differences also emerged between school types at the secondary level. These findings suggest that within the secondary level, CLIL teachers employed at secondary schools with a technical orientation (HTL) tended to score consistently lower on all indicators of professional well-being relating to their role as CLIL teachers than their colleagues in general secondary schools (AHS). Though we cannot necessarily determine the reasons for these differences, a potentially relevant contextual difference is that CLIL teaching in Austria is mandatory at HTL, but not at AHS schools (BGBl II Nr. 300, 2011). Generally, teachers trained in Austria are subject area specialists that have not generally received language or language pedagogy training (Hüttner, DaltonPuffer \& Smit, 2013).

The study also provides initial insights into reported beliefs and attitudes positively and negatively associated with the professional well-being of secondary CLIL and tertiary EMI teachers. For example, feeling adequately trained to teach CLIL/EMI courses, having positive attitudes towards CLIL/EMI, feeling that CLIL/EMI is beneficial for students' L2 development, and perceiving that students enjoy CLIL/EMI were all positively associated. Contrastingly, perceived stress during CLIL/EMI teaching and beliefs that teaching CLIL/EMI classes negatively affected the teachers' work-life balance were negatively related to the reported sense of overall professional wellbeing for both groups. For tertiary EMI teachers, both professional well-being and job satisfaction were negatively affected when EMI teaching was perceived to negatively affect their work-life balance. University teaching is often characterized as a high-autonomy profession, but also a profession where boundaries between work and other domains tend to blur (Davies \& Jenkins, 2013). This can create conflicts for educators. For instance, in a 2013 study, Kinman and Wray found that experiencing a substantial conflict between the work and private domains was "the strongest predictor of psychological distress" for tertiary level educators (p. 7). These findings suggest that interventions at the tertiary level should address the possible conflicts between various domains and how to manage these in ways that educators themselves would deem healthy for their own lives.

Further differences between secondary CLIL and tertiary EMI teachers emerged in terms of job attitudes and beliefs captured in the survey. Secondary CLIL teachers scored less favorably on a number of beliefs and attitudes related to professional well-being as compared to the EMI instructors at tertiary level, and these may, in part, help to explain observed differences in professional well-being between the two groups. The fact that the differences between the two groups in the survey related to the CLIL/EMI specific measures may provide some indication that phenomena specifically related to CLIL/EMI teaching may account for the between-group differences in professional well-being. Though important between-group differences were found in these teachers' beliefs and attitudes and CLIL/EMI specific well-being these differences could also possibly be influenced by the inherent characteristics of teaching at the secondary and tertiary levels. Future studies should consider measuring both CLIL/EMI specific well-being and as well general professional well-being and consider whether differences emerge in both or just in terms of CLIL/EMI. 
Further important differences in CLIL-related attitudes and beliefs emerged at the secondary level between AHS and HTL schools. For instance, perceptions from the teachers about whether CLIL was the best way to teach the subject, or in other words, if they believed in the effectiveness of CLIL was endorsed less often for HTL teachers than with AHS teachers. This is particularly notable as this question was associated with teachers' professional well-being and may partly account for differences observed between HTL and AHS teachers in this regard. Other dimensions also may have affected these differences, including whether or not CLIL teachers felt they had a special status at the school and whether the school administration and other colleagues viewed CLIL teaching favorably. Both of these factors were also associated with teachers' CLIL specific well-being and may also partially account for the differences in well-being observed between teachers at AHS and HTL type schools.

Perhaps most importantly, the finding that teachers who felt they had received adequate training for undertaking CLIL/EMI teaching tended to experience higher well-being in their professional teaching roles highlights the importance of CLIL-specific teacher training components as part of the curriculum for school teachers, and EMIspecific professional development courses offered to teachers at the university-level. This finding is encouraging and offers hope that professional development can make a significant difference in novel contexts such as CLIL/EMI programs.

\section{CONCLUSION}

This study investigated secondary CLIL and tertiary EMI teacher well-being, job satisfaction, job beliefs and attitudes. In doing so, similarities and differences between these samples emerged. Whereas these teachers did not differ significantly in terms of their senses of job satisfaction, secondary CLIL teachers scored consistently lower overall in terms of their well-being as it relates to their CLIL/EMI courses than tertiary EMI teachers. As CLIL and EMI programs continue to spread, teachers' practices and roles in secondary CLIL and tertiary EMI contexts will continue to expand in terms of scope and scale. Given the large number of teachers affected by these changes, the development of CLIL and EMI specific professional development programs are clear concerns. An encouraging finding of this study worth repeating is that those teachers who felt prepared to teach CLIL/EMI, tended to have higher well-being overall. The findings on teachers' beliefs and attitudes related to professional well-being suggest further that effective ways of supporting students' L2 development and resource-effective ways of developing CLIL materials, as well as highlighting the creative element in this process may be key topics in helping to promote professional wellbeing of CLIL teachers and EMI instructors. In this respect, more research is needed on teachers' beliefs and attitudes associated with professional well-being so that these can be suitably addressed in teacher training programs.

Through its predominantly quantitative survey methodology, the present study is limited to identifying larger trends regarding the professional well-being and job satisfaction among teachers in both groups, while its potential for generating explanations for the observed patterns is limited. That said, the larger trends obtained can be read together with the themes that emerged from the exploratory interview study conducted by Talbot et al. (2021) with secondary CLIL and tertiary EMI teachers in Austria. In line with the trends reported here, it suggested that CLIL teachers at the secondary level may be more at risk in terms of their professional well-being than their colleagues at tertiary level. The interviewed secondary CLIL teachers tended to perceive a higher workload, feel more responsible for the language learning outcomes of their CLIL students and express more sensitivity about how their occupation was perceived in Austria than their tertiarylevel peers, some of which were found to be significantly associated with professional well-being in the quantitative analysis reported here. Future mixed methods inquiries that explore the general trends obtained further from an emic perspective with a sub-sample of participants would be particularly welcome.

Methodologically, the present study contributes with a CLIL-/EMI-specific version of the SWLS and PERMA scales, which are available to researchers working in this area. As professional well-being and job satisfaction relate to teacher effectiveness (Barber \& Mourshed, 2007; Kunter et al., 2013) and have been shown to be related to the quality of learning (Spilt, Koomen \& Thijs, 2011), comprehensive research programs are needed in order to better understand and support the experience of all language teachers, but 
especially those in novel and/or challenging roles, as is the case of the increasing number of CLIL teachers and EMI instructors in Austria, and globally. The field of L2 teacher psychology may be regarded as playing a key role in this regard, enhancing the experience of teachers and learners in all instructed L2 learning contexts.

\section{Acknowledgements}

Findings are part of a nationwide study funded by ÖNB grant no. 17136. We would like to thank Nicole Hofstadler and all of the extended research team who contributed to the project entitled: Selbstbild \& professionelles Wohlbefinden von CLIL Lehrenden. More information on the project can be found by following the link below:

https://www.oenb.at/jublfonds/jublfonds/projectsearch?id=6059\&action=detailview\&origin=resultlist

\section{Notes on the authors}

Gianna Hessel is a Postdoctoral Research Fellow at the ELT Research and Methodology Section at the University of Graz, Austria. Her research focuses on the psychology of second language learning and teaching with an emphasis on L2 self-motivation.

Kyle R. Talbot is a language teacher and researcher in Applied Linguistics. His current research and thinking interests include the psychology of language learning and teaching, bilingual and multilingual education, and applied complexity science.

Marie-Theres Gruber works at the KPH Graz, Austria. Her research interests are early foreign language learning, lesson planning and CLIL as well as progressive pedagogies (Jenaplan) and diversity management. She has been involved in different CLIL projects and CLIL in German material development for the Austrian language competence center (ÖSZ).

Sarah Mercer is Professor of Foreign Language Teaching at the University of Graz, Austria, where she is Head of ELT methodology. Her research interests include all aspects of the psychology surrounding the foreign language learning experience. She is the author, co-author and co-editor of several books in this area.

\section{REFERENCES}

Aguilar, M. (2017). Engineering lecturers' views on CLIL and EMI. International Journal of Bilingual Education and Bilingualism, 20(6), 722-735. https://doi.org/10.1080/13670050.2015.1073664

Ascenso, S., Perkins, R., \& Williamon, A. (2018). Resounding meaning: A PERMA wellbeing profile of classical musicians. Frontiers in Psychology, 9, 1895. https://doi.org/10.3389/fpsyg.2018.01895

Bajorek, Z., Gulliford, J., \& Taskila, T. (2014). Healthy teachers, higher marks? Establishing a link between teacher health and wellbeing, and student outcomes. The Work Foundation.

https://www.educationsupport.org.uk/sites/default/ files/resources/healthy_teachers_higher_marks_re port $0 . p d f$
Bricheno, P., Brown, S., \& Lubansky, R. (2009). Teacher wellbeing: A review of the evidence. https://www.scribd.com/doc/25759578/TeacherWellbeing-A-research-of-the-evidence

Barber, M., \& Mourshed, M., \& McKinsey, C. (2007). How the world's best-performing school systems come out on top. http://lst-iiep.iiep-unesco.org/cgibin/wwwi32.exe/[in=epidoc $1 . i n / / ? \mathrm{t} 2000=025763 /($ $\underline{100)}$

Bundesministerium für Unterricht, Kunst und Kultur. (2011). Lehrpläne der Höheren technischen und gewerblichen Lehranstalten. Dokument Nr. BGBLA_2011_II_300 in der Fassung vom 7. September 2011.

https://www.ris.bka.gv.at/eli/bgbl/II/2011/300

Bundesministerium für Unterricht, Kunst und Kultur. (2000). Lehrpläne Lehrpläne der allgemeinbildenden höheren Schulen. Dokument 
Nr. 2000_133_2 in der Fassung vom 11. Mai 2000.

https://rdb.manz.at/document/ris.c.BGBL_OS_200 00511_2_133

Bovellan, E. (2014). Teachers' beliefs about learning Content and Language Integrated Learning (CLIL). [Doctoral dissertation, University of Jyväskylä].

https://jyx.jyu.fi/bitstream/handle/123456789/4427 7/978-951-39-5809-

1 vaitos20092014.pdf? sequence

Brunsting, N. C., Sreckovic, M. A., \& Lane, K. L. (2014). Special education teacher burnout: A synthesis of research from 1979 to 2013. Education and Treatment of Children, 37(4), 681-711. https://doi.org/10.1353/etc.2014.0032

Burke, R. J., Greenglass, E. R., \& Schwarzer, R. (1996). Predicting teacher burnout over time: Effects of work stress, social support, and self-doubts on burnout and its consequences. Anxiety, Stress \& Coping, 9(3), 261-275. https://doi.org/10.1080/10615809608249406

Butler, J., \& Kern, M. L. (2016). The PERMA-Profiler: A brief multidimensional measure of flourishing. International Journal of Wellbeing, 6(3), 1-48. https://doi.org/10.5502/ijw.v6i3.526

Byrne, B. M. (1999). The nomological network of teacher burnout: A literature review and empirically validated model. In R. Vandenberghe, \& A. M. Huberman (Eds.), Understanding and preventing teacher burnout: A sourcebook of international research and practice (pp. 15-37). Cambridge University Press. https://doi.org/10.1017/cbo9780511527784.003

Cammarata, L., \& Tedick, D. J. (2012). Balancing content and language in instruction: The experience of immersion teachers. The Modern Language Journal, 96(2), 251-269.

https://doi.org/10.1111/j.1540-4781.2012.01330.x

Caprara, G. V., Barbaranelli, C., Steca, P., \& Malone, P. S. (2006). Teachers' self-efficacy beliefs as determinants of job satisfaction and students' academic achievement: A study at the school level. Journal of School Psychology, 44(6), 473490. https://doi.org/10.1016/j.jsp.2006.09.001

Coyle, D., Hood, P., \& Marsh, D. (2010). CLIL: Content and language integrated learning. Cambridge University Press.

Dalton-Puffer, C., \& Nikula, T. (2006). Pragmatics of content-based instruction: Teacher and student directives in Finnish and Austrian classrooms. Applied Linguistics, 27(2), 241-267. https://doi.org/10.1093/applin/aml007

Dalton-Puffer, C. (2011). Content-and-language integrated learning: From practice to principles? Annual Review of Applied Linguistics, 31, 182-204. https://doi.org/10.1017/s0267190511000092

Davies, E., \& Jenkins, A. (2013). The work-to-retirement transition of academic staff: Attitudes and experiences. Employee Relations, 35(3), 322-338. https://doi.org/10.1108/01425451311320503

Day, C. (2017). Teachers' worlds and work:

Understanding complexity, building quality.

Routledge. https://doi.org/10.4324/9781315170091-8

Day, C., Sammons, P., Stobart, G., Kington, A., \& Gu, Q. (2007). Teachers matter: Connecting work, lives and effectiveness. Open University Press.

Dearden, J. (2015). English as a medium of instruction: A growing global phenomenon. British Council. https://www.britishcouncil.org/education/ihe/know ledge-centre/english-languagehighereducation/report-english-medium-instruction

Deci, E., \& Ryan, R. (1980). Self-determination theory: When mind mediates behavior. The Journal of Mind and Behavior, 1(1), 33-43.

Dewberry, C., \& Briner, R. (2007). Report for worklife support on the relation between well-being and climate in schools and pupil performance. Worklife Support.

Diener, E., Emmons, R. A., Larsen, R. J., \& Griffin, S. (1985). The satisfaction with life scale. Journal of 
Personality Assessment, 49, 71-75. https://doi.org/10.1207/s15327752jpa4901_13

Doane, D. P., \& Seward, L. E. (2011). Applied statistics in business and economics (4th edn). McGraw-Hill Education.

Efron, B., \& Tibshirani, R. J. (1993). An introduction to the bootstrap. Chapman \& Hall.

Farber, B. A. (1991). Crisis in education: Stress and burnout in the American teacher. Jossey-Bass.

Frenzel, A. C., Goetz, T., Lüdtke, O., Pekrun, R., \& Sutton, R. E. (2009). Emotional transmission in the classroom: exploring the relationship between teacher and student enjoyment. Journal of Educational Psychology, 101(3), 705-716. https://doi.org/10.1037/a0014695

Goodman, F. R., Disabato, D. J., Kashdan, T. B., \& Kauffman, S. B. (2018). Measuring well-being: A comparison of subjective well-being and PERMA. The Journal of Positive Psychology, 13(4), 321332.

https://doi.org/10.1080/17439760.2017.1388434

Greenberg, M. T. (2017). Foreword 2. In T. M. McIntyre, S. E. McIntyre, \& D. J. Francis (Eds.), Educator stress: An occupational health perspective (pp. ix$\mathrm{x})$. Springer International.

Hakanen, J. J., Bakker, A. B., \& Schaufeli, W. B. (2006). Burnout and work engagement among teachers. Journal of School Psychology, 43(6), 495-513. https://doi.org/10.1016/j.jsp.2005.11.001

Hills, P., \& Argyle, M. (2001). Happiness, introversionextraversion and happy introverts. Personality and Individual Differences, 30, 595-608. https://doi:10.1016/S0191-8869(00)00058-1

Hofstadler, N., Talbot, K., Mercer, S., \& Lämmerer, A. (2020). The thrills and ills of CLIL. In C. Gkonou, J.-M. Dewaele, \& J. King (Eds.), The emotional rollercoaster of language teaching (pp. 13-30). Multilingual Matters. https://doi.org/10.21832/9781788928342-006

Hüttner, J., Dalton-Puffer, C., \& Smit, U. (2013). The power of beliefs: Lay theories and their influence on the implementation of CLIL programmes.
International Journal of Bilingual Education and Bilingualism, 16(3), 267-284. https://doi.org/10.1080/13670050.2013.777385

Iasiello, M., Bartholomaeus, J., Jarden, A., \& Kelly, G. (2017). Measuring PERMA+ in South Australia, the state of wellbeing: A comparison with national and international norms. Journal of Positive Psychology and Wellbeing, 1(2), 53-72. http://www.journalppw.com/index.php/JPPW/artic le/view/12

Judge, T. A., \& Klinger, R. (2008). Job satisfaction: Subjective well-being at work. In M. Eid, \& R. J. Larsen (Eds.), The science of subjective well-being (pp. 393-413). Guilford Press.

Kahneman, D., Krueger, A. B., Schkade, D. A., Schwarz, N., \& Stone, A. A. (2004). A survey method for characterizing daily life experience: The day reconstruction method. Science, 306(5702), 17761780. https://doi.org/10.1126/science.1103572

Kinman, G., \& Wray, S. (2013). Higher stress: A survey of stress and well-being among staff in higher education.

https://www.ucu.org.uk/media/5911/Higher-stressa-survey-of-stress-and-well-being-among-staff-inhigher-education-Jul13/pdf/HE_stress_report_July_2013.pdf

Klassen, R. M., \& Chiu, M. M. (2010). Effects on teachers' self-efficacy and job satisfaction: Teacher gender, years of experience, and job stress. Journal of Educational Psychology, 102(3), 741-756. https://doi.org/10.1037/a0019237

Kunter, M., Klusmann, U., Baumert, J., Richter, D., Voss, T., \& Hachfeld, A. (2013). Professional competence of teachers: Effects on instructional quality and student development. Journal of Educational Psychology, 105(3), 805-820. https://doi.org/10.1037/a0032583

Macaro, E., Curle, S., Pun, J., An, J., \& Dearden, J. (2018). A systematic review of English medium instruction in higher education. Language Teaching, 51(1), 36-76. https://doi.org/10.1017/S0261444817000350 
MacIntyre, P. D., Ross, J., Talbot, K., Mercer, S., Gregersen, T., \& Banga, C. A. (2019). Stressors, personality and wellbeing among language teachers. System, 82, 26-38. https://doi.org/10.1016/j.system.2019.02.013

McIntyre, T. M., McIntyre, S. E., \& Francis, D. J. (Eds.). (2017). Educator stress: An occupational health perspective. Springer International. https://doi.org/10.1007/978-3-319-53053-6

Mehisto, P., Marsh, D., \& Frigols, M. J. (2009). Uncovering CLIL: Content and language integrated learning in bilingual and multilingual education. Macmillan.

Moate, J. M. (2011). The impact of foreign language mediated teaching on teachers' sense of professional integrity in the CLIL classroom. European Journal of Teacher Education, 34(3), 333-346.

https://doi.org/10.1080/02619768.2011.585023

Nussbaum, M. (2003). Capabilities as fundamental entitlements: Sen and social justice. Feminist Economics, 9(2-3), 33-59. https://doi.org/10.1080/1354570022000077926

Ostroff, C. (1992). The relationship between satisfaction, attitudes, and performance: An organizational level analysis. Journal of Applied Psychology, 77(6), 963-974. https://doi.org/10.1037/0021$\underline{9010.77 .6 .963}$

Pappa, S., Moate, J., Ruohotie-Lyhty, M., \& Eteläpelto, A. (2017). Teachers' pedagogical and relational identity negotiation in the Finnish CLIL context. Teaching and Teacher Education, 65, 61-70. https://doi.org/10.1016/j.tate.2017.03.008

Pavot, W., \& Diener, E. (2013). The satisfaction with life scale (SWLS). Measurement instrument database for the social science. www.midss.ie

Pavot, W., Diener, E., Colvin, C. R., \& Sandvik, E. (1991). Further validation of the satisfaction with life scale: Evidence for the cross-method convergence of well-being measures. Journal of Personality Assessment, 57(1), 149-161. https://doi.org/10.1207/s15327752jpa5701_17
Ryff, C. D. (1989). Happiness is everything, or is it? Explorations on the meaning of psychological well-being. Journal of Personality and Social Psychology, 57(6), 1069-1081. https://doi.org/10.1037/0022-3514.57.6.1069

Schmidt-Unterberger, B. (2018). The English-medium paradigm: A conceptualisation of English-medium teaching in higher education. International Journal of Bilingual Education and Bilingualism, 21(5), 527-539. https://doi.org/10.1080/13670050.2018.1491949

Seligman, M. E. P. (2011). Flourish. A visionary new understanding of happiness and well-being. Free Press. https://doi.org/10.5860/choice.48-7217

Smit, U., \& Dafouz, E. (2012). Integrating content and language in higher education. An introduction to English-medium policies, conceptual issues and research practices across Europe. AILA Review 25, 1-12. https://doi.org/10.1075/aila.25.01smi

Spilt, J. L., Koomen, H. M. Y., \& Thijs, J. T. (2011). Teacher wellbeing: The importance of teacherstudent relationships. Educational Psychology Review, 23(4), 457-477. https://doi.org/10.1007/s10648-011-9170-y

Talbot, K., \& Mercer, S. (forthcoming). Language teacher well-being. In H. Mohebbi, \& C. Coombe (Eds.), Research questions in language education: A reference guide for teachers. Springer.

Talbot, K. R., Mercer, S., Gruber, M.-T., Lämmerer, A., \& Hofstadler, N. (2021). Comparatively speaking: CLIL/EMI teacher well-being at the primary, secondary and tertiary levels in Austria. In K. R. Talbot, M.-T. Gruber, \& R. Nishida (Eds.), The psychological experience of integrating content and language. Multilingual Matters.

Toker, S., Melamed, S., Berliner, S., Zeltser, D., \& Shapira, I. (2012). Burnout and risk of coronary heart disease: A prospective study of 8838 employees. Psychosomatic Medicine, 74(8), 840847. https://doi.org/10.1097/PSY.0b013e31826c3174 
Unterberger, B., \& Wilhelmer, N. (2011). English-medium education in economics and business studies: Capturing the status quo at Austrian universities. ITL - International Journal of Applied Linguistics, 161, 90-110. https://doi.org/10.1075/itl.161.06unt

Vinke, A. A., Snippe, J., \& Jochems, W. (1998). Englishmedium content courses in non-english higher education: A study of lecturer experiences and teaching behaviours. Teaching in Higher Education, 3(3), 383-394. https://doi.org/10.1080/1356215980030307

Wächter, B., \& Maiworm, F. (2014). English-taught programmes in European higher education: The state of play in 2014. Lemmens Medien.
Williams, D. (2015). A systematic review of EMI and implications for the South Korean HE context. ELT World Online, 1-23.

https://blog.nus.edu.sg/eltwo/2015/04/27/asystematic-review-of-english-medium-instructionemi-and-implications-for-the-southkoreanhighereducation-context-2/

Wright, T. A., \& Bonett, D. G. (2007). Job satisfaction and psychological well-being as nonadditive predictors of workplace turnover. Journal of Management, 33(2), 141-160.

https://doi.org/10.1177/0149206306297582 